\title{
Bakailao-gibel olio fresko eta oxidatuaren urdail-hesteetako in vitro digestioa: BSA eta BHTren propietate antioxidatzaileen eta azken honetatik eratorritako metabolitoen azterketa
}

\author{
(In vitro gastrointestinal digestion of fresh and oxidized cod liver oil: \\ study of the antioxidant properties of BSA and BHT, \\ and of BHT-derived metabolites)
}

\author{
Bárbara Nieva-Echevarría*, Encarnación Goicoechea, María D. Guillén
}

Elikagaien Teknologia Arloa, Farmazia eta Elikagaien Zientziak Saila, (UPV/EHU)

\begin{abstract}
LABURPENA: Ikerketa honen helburua da behi-seroalbumina proteinak (BSA) eta 2,6-di-tert-butil-hidroxitolueno (BHT, E-321 gehigarria) antioxidatzaile fenolikoak bakailao-gibel olio fresko eta oxidatuaren in vitro digestioan gertatutako oxidazio erreakzioetan duten efektua aztertzea. Halaber, kondizio horietan gerta daitekeen BHTren degradazioa eta hori hainbat metabolito bihurtzea ere aztertu zen. Lipidoen oxidazio-produktu sekundarioen izaera eta kantitatea zein BHTren pisu molekular baxuko metabolitoak aztertzeko erabilitako teknika hau izan zen: Fase Solidoko Mikroerauzketa eta ondoren GasKromatografia/ Masa-Espektrometria (SPME-GC/MS). In vitro digestioaren ondoren jasotako digestatoen buru-gunean aurkitutako 90 konposatu lurrunkorren ugaritasunetan oinarrituz, BSAk eta BHTek efektu antioxidatzaile argia zutela ikusi zen: lehena izan zen bietan eraginkorrena lan honen kondizioetan, batik bat oxidatutako olioaren digestioan. Bestalde, oxidatutako olioaren digestioan zehar BHT modu nabarmenean degradatu zela ikusi zen. Horren ondorioz, 2,6-di-tert-butil-4-hidroxi-4-metil-2,5-ziklohexadien-1-ona (BHT-OH), 2,6-di-tert-butil-2,5-ziklohexadien-1,4-diona (BHT-Q) eta 3,5-di-tert-butil4-hidroxi-benzaldehidoa (BHT-CHO) metabolito lurrunkor nagusien handitzea gertatu zen.
\end{abstract}

HITZ GAKOAK: antioxidatzaile fenolikoa; BHT; BSA; digestioa; oxidazio-konposatu lurrunkorrak; proteina.

\begin{abstract}
This study was aimed to investigate the effect of bovine serum albumin (BSA) protein and the phenolic antioxidant 2,6-di-tert-butyl-hydroxytoluene (BHT, additive E-321) on the oxidation reactions taking place during in vitro gastrointestinal digestion of fresh and oxidized cod liver oil. Likewise, the potential degradation of BHT under these conditions and transformation into different metabolites was addressed. The technique employed to study the nature and amount of lipid secondary oxidation products, as well as the BHT-metabolites of low molecular weight, present in the digestates was studied by Solid Phase Microextraction followed by Gas Chromatography/ Mass Spectrometry (SPME-GC/MS). Based on the abundances of 90 volatile compounds detected in the headspace of the digestates, it could be observed that both BSA and BHT had a clear antioxidant effect. In the conditions of this study, the former showed to be more effective than the latter, specially in the case of oxidized oil digestion. In addition, it was highlighted that BHT notably degraded during digestion of oxidized oil. As consequence, the main volatile metabolites 2,6-di-tert-butyl-4-hydroxy-4-methyl-2,5-cyclohexadien-1-one (BHT-OH), 2,6di-tert-butyl-2,5-cyclohexadien-1,4-dione (BHT-Q) and 3,5-di-tert-butyl-4-hydroxy-benzaldehyde (BHT-CHO) increased.
\end{abstract}

KEYWORDS: BHT; BSA; digestion; phenolic antioxidant; protein; volatile oxidation products.

* Harremanetan jartzeko / Corresponding author: Bárbara Nieva-Echevarría. Elikagaien Teknologia Arloa, Farmazia eta Elikagaien Zientziak Saila, Farmazia Fakultatea, Lascaray Ikergunea, Universidad del País Vasco/Euskal Herriko Unibertsitatea (UPV/EHU), Unibertsitateko Ibilbidea, 7 (01006 Vitoria-Gasteiz, Araba/Álava, Euskal Herria). - barbara.nieva@ehu.eus https://orcid.org/0000-0002-6769-2932.

Nola aipatu / How to cite: Nieva-Echevarría, Bárbara; Goicoechea, Encarnación; Guillén, María D. (2020). «Bakailao-gibel olio fresko eta oxidatuaren urdail-hesteetako in vitro digestioa: BSA eta BHTren propietate antioxidatzaileen eta azken honetatik eratorritako metabolitoen azterketa»; Ekaia, 38, 2020, 183-198. (https://doi.org/10.1387/ekaia.20863).

Jasoa: 15 maiatza, 2019; Onartua: 07 apirila, 2020.

ISSN 0214-9001 - eISSN 2444-3255 / (c) 2020 UPV/EHU

cc)(1)(2) Obra hau Creative Commons Atribución 4.0 Internacional-en

BY NC SA lizentziapean dago 


\section{SARRERA}

Tradizionalki, Norvegian, Islandian, Danimarkan eta Erresuma Batuan bakailao-gibel olioa kontsumitu da eguneroko dietaren barruan, batik bat kostako zonaldeetan. Azken hamarkadetan asko hazi da haren kontsumoa nutrizio-gehigarri moduan, bai kapsuletan bai aberastutako elikagaietan, bereziki Europan eta Amerikako Estatu Batuetan (AEB). Arrazoia da esaten dela, alde batetik, A eta D bitaminen gabezia saihesten laguntzen duela, eta, bestetik, haren kate luzeko omega-3 lipido poliasegabeek osasunerako propietate onuragarriak dituztela, hau da, dokosahexae-

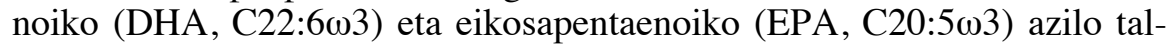
deek [1, 2]. Hala ere, azken lipido horiek hain asegabeak direnez, oso ezegonkorrak dira, eta baldintza batzuetan, adibidez prozesatze teknologikoan edo biltegiratzean, oso erraz oxidatzen dira [3]. Ondorioz, potentzialki toxikoak izan daitezkeen oxidazio-konposatuak sor daitezke, eta haien izaeraren eta kantitatearen arabera, agian lehen aipatutako propietate onuragarriak indargabetzen dira [4].

Gai honetan sakontzeko, funtsezkoa da aztertzea lehenengo pausua, hau da, zer gertatzen zaion bakailao-gibel olioari behin irentsita, urdail-hesteetako digestio-prozesuan zehar. Gaur egun arte soilik sei artikulu zientifiko argitaratu dira arrain-olio eta -emultsioen in vitro digestioaren gainean [5-10]. Espero zenez, ikerketa hauetan guztietan ikusi zen lipidoen oxidazioa gertatzen dela. Hala ere, informazio gehiago behar da arrain-lipidoen in vitro digestioan sortutako oxidazio-produktuen izaera espezifikoari buruz, aipatutako aurreko ikerketan batik bat metodologia ez-espezifikoak [3] erabili zirelako: esaterako, Peroxidoen Balorea (PV) edo Azido tiobarbiturikoarekin erreakzionatzen duten substantzien (TBARS) testa [5-7] edo agian hiruzpalau oxidazio-konposatu baino ez ziren aztertu (malondialdehidoa, 4-hidroxi-2-hexenala, 4-hidroxi-2-nonenala eta 4-oxo-2nonenala) $[8,10]$. Artikulu batean bakarrik erabili ziren lipidoen oxidazioaren gainean ikuspegi orokorra ematen duten teknikak [9]: Protoi Erresonantzia Magnetiko Nuklearra ( ${ }^{1} \mathrm{H}$ NMR), zeinak aztertzen duen zenbateraino oxidatzen diren azilo talde/gantz azido asegabeak eta zein oxidazio-konposatu primario eta sekundario sortzen diren, eta Fase Solidoko Mikroerauzketa-Gas-Kromatografia/ Masa-Espektrometria (SPME-GC/MS), zeinak analizatzen dituen zein oxidazio-konposatu sekundario hegazkor sortzen diren.

Elikagai-industrian olio eta gantzen oxidazioa atzeratzeko erabiltzen diren gehigarri antioxidatzaile sintetikoen artean, 2,6-di-tert-butil-hidroxitoluenoa (BHT, E-321) aipa daiteke [11]. Aztertu da haragiaren, koltzaolioaren eta bakailao-gibel olioaren in vitro eta in vivo digestioetan BHTk duen eragina gertatutako lipidoen oxidazioan, baina emaitza kontrajarriak ikusi dira bere ahalmen antioxidatzaileari dagokionez [9, 12, 13]. Horien arrazoiak honako hauek izan daitezke: a) baldintza esperimental desberdi- 
nak erabiltzea (urdaileko versus urdail-hesteetako digestioa), b) BHTren kontzentrazio desberdinak erabiltzea (20-10.000 mg/Kg jaki), edo c) laginen oxidazio-maila neurtzeko erabilitako metodologiak: PV, TBARS edo absorbantzia $234 \mathrm{~nm}$-tan (inespezifikoak) versus teknika kromatografikoak eta espektroskopikoak (espezifikoak). Gainera, lan horietako batean in vitro digestioan gertatutako BHTren degradazioa eta metabolitoen sorrera aztertu zen [9], oso interesgarria dena, kontuan izanda BHT-metabolito batzuek baldintza batzuetan toxikotasuna erakutsi dutela [11].

Alabaina, jaki gehienak ez daude lipidoz bakarrik osatuta, baizik eta beste osagai batzuez ere, adibidez, proteinaz. Gauzak horrela, proteinen presentziak elikadura-boloan eragin handia izan dezake lipidoen oxidazioan. Digestio-prozesuan, lipidoekin eta karbohidratoekin gertatzen den bezala, dietako proteinak hidrolizatu egiten dira, eta tamaina txikiko konposatu xurgagarri bihurtzen dira. Ondorioz, heste-lumenean hainbat funtzio dituzten peptido eta aminoazidoak aurkitu daitezke, esaterako, ahalmen antioxidatzailea dutenak [14]. Izan ere, aipatu behar da azken ikerketetan aurkitu dela proteina askoko zenbait jakiren in vitro digestioan askatutako peptidoek aktibitate antioxidatzailea zutela, adibidez, egositako arrautzetan [15] eta zamo arrunt arrainaren muskuluan [16]. Dena dela, azpimarratzekoa da azterlan horietan erabilitako metodologiak erradikal askeak neurtzen dituzten test kimikoak direla - Oxigeno-erradikalak absorbatzeko gaitasuna (ingelesez ORAC), 2,20-azino-bis(azido 3-etilbentzotiazolin-6-sulfonikoa) (ingelesez ABTS), 2,20-difenil-1-pikrilhidraziloaren testa (ingelesez DPPH), zeinen desabantaila eta mugengatik ez diren gai erakusteko aminoazidoen eta peptidoen eragina lipidoen oxidazio-mekanismoetan [17]- .

Testuinguru honetan, ikerlan honek aztertzen du nolako efektua duten, alde batetik, BHT antioxidatzaileak eta, bestetik, behi-seroalbumina (BSA) proteinak, bakailao-gibel olio freskoaren eta oxidatuaren urdail-hesteetako in vitro digestioan gertatutako oxidazio erreakzioetan. Horretarako, digestio aurretik eta ondoren laginen buru-gunean dauden konposatu hegazkorrak analizatuko dira SPME-GC/MS teknikaren bidez. Horrek informazio handia emango du lipidoetatik sortutako oxidazio-konposatu sekundarioen gainean, ez bakarrik haiek identifikatzeko, baizik eta semi-kuantifikatzeko ere, lagina aldez aurretik kimikoki aldatzeko beharrik gabe (zeinek bermatzen duen emaitzen egiazkotasuna). Orobat aztertuko da ea digestio-prozesu honetan BHT-metabolitoak sortzen diren.

\section{MATERIALAK ETA METODOAK}

\subsection{Hasierako olio laginak}

Bakailao-gibel olio freskoa (O) farmazia-bulego batean erosi zen. Olio mota hori aukeratu zen omega-3 azilo talde poliasegabeetan oso aberatsa 
delako, lehen aipatu bezala, eta, horrenbestez, azkarrago oxidatzeko joera duelako. Etiketak dioen bezala, olio horrek ez dauka gehigarririk. Bakailao gibel-olio oxidatua (Ox) lortzeko, erositako olio freskoa labe batean berotu zen $70{ }^{\circ} \mathrm{C}$-an 20 orduz (biltegiratze azeleratuaren egoera). Bi olio mota horiei $(\mathrm{O}, \mathrm{Ox})$ gehitu zitzaien, alde batetik, 2,6-di-tert-butil-hidroxitoluenoa (BHT) (Sigma-Aldrich, St. Louis, MO, AEB), eta, bestetik, behi-seroalbumina (BSA) proteina (Sigma-Aldrich).

Olio freskoaren eta oxidatuaren hainbat azpilagini BHT gehigarri antioxidatzailea gehitu zitzaion, kontzentrazio hauetan: $20 \mathrm{mg} / \mathrm{Kg}$ olio (O1, Ox1), $200 \mathrm{mg} / \mathrm{Kg}$ olio (O2, Ox2) eta $800 \mathrm{mg} / \mathrm{Kg}$ olio (O3, Ox3). Azpimarratu behar da 1129/2011 Europako Araudiak olio jangarrietan ezartzen duen gehienezko BHT dosia $100 \mathrm{mg} / \mathrm{Kg}$ olio dela [18].

Era berean, olio freskoari eta oxidatuari BSA proteina ere gehitu zitzaien (1,3 g BSA: 0,5 g olio lagin) (O + BSA, Ox + BSA). Proteina:lipido proportzio hori aukeratu zen, arrain erdi-gantzatsuetan aurkitzen dena delako; adibidez, lupian (Dicentrarchus labrax).

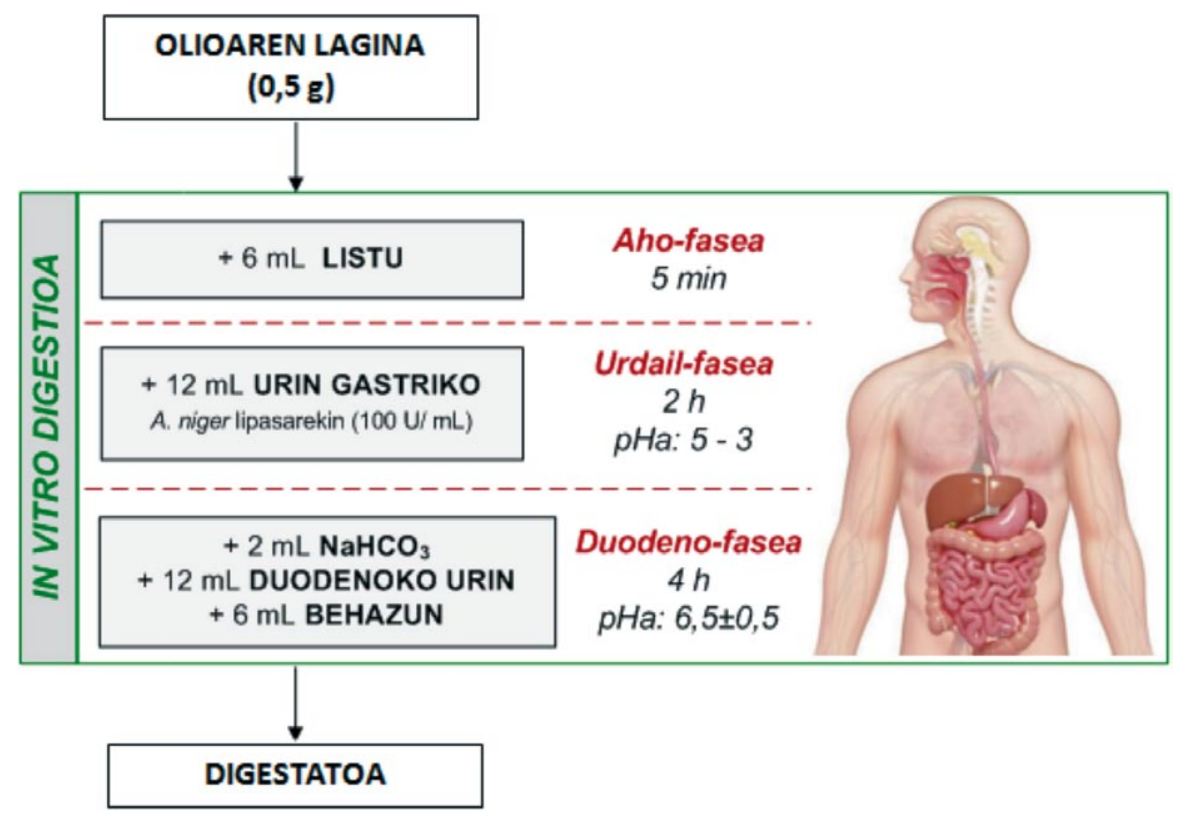

1. irudia. Urdail-hesteetako in vitro digestioan erabilitako eredu estatikoaren eskema $[19,20]$. 


\subsection{Urdail-hesteetako in vitro digestioen esperimentuak}

Lehen aipatutako olio-laginak $(\mathrm{O}, \mathrm{O} 1, \mathrm{O} 2, \mathrm{O} 3, \mathrm{O}+\mathrm{BSA}$ eta $\mathrm{Ox}, \mathrm{Ox} 1$, Ox2, Ox3, Ox + BSA) urdail-hesteetako in vitro eredu estatiko baten bidez digeritu ziren $(0,5 \mathrm{~g}$ olio bakoitzeko) $[19,20]$. Digestio-urin guztiak (listua, urin gastrikoa, duodenoko urina eta behazuna) prestatzeko erabilitako erreaktiboak Sigma-Aldrich enpresan erosi ziren. 1. taulan azaltzen da digestio-urin horien konposizioa. In vitro eredu estatiko horrek hiru etapa ditu, ahoan, urdailean eta duodenoan gertatzen diren digestio-prozesuak imitatzeko (ikusi 1. irudia). Lagin bakoitza bi aldiz digeritu zen, eta lortutako laginak (digestatoak) horrela izendatu ziren: DO, DO1, DO2, DO3, DO + BSA eta DOx, DOx1, DOx2, DOx3, DOx + BSA; guztira 20 digestato lortu ziren digeritu ondoren. Digestio-esperimentu bakoitzean, aldi berean lagin zuri bat (Z izenekoa) digeritu zen, hau da, oliorik gabe.

1. taula. digestio-urinen konposizioa eta $\mathrm{pHa}$. Osagai batzuen kodea Sigma-Aldrich enpresaren katalogoan ere ematen dira.

\begin{tabular}{|c|c|c|c|c|}
\hline Osagaiak & Listua & $\begin{array}{c}\text { Urin } \\
\text { gastrikoa }\end{array}$ & $\begin{array}{l}\text { Duodenoko } \\
\text { urina }\end{array}$ & Behazuna \\
\hline $\mathrm{KCl}(\mathrm{mmol} / \mathrm{L})$ & 12,02 & 11,06 & 7,57 & 5,05 \\
\hline $\mathrm{NaCl}(\mathrm{mmol} / \mathrm{L})$ & 5,10 & 47,09 & 119,98 & 89,99 \\
\hline $\mathrm{NaHCO}_{3}(\mathrm{mmol} / \mathrm{L})$ & 20,17 & - & 40,33 & 68,86 \\
\hline $\mathrm{NaH}_{2} \mathrm{PO}_{4}(\mathrm{mmol} / \mathrm{L})$ & 7,40 & 0,22 & - & - \\
\hline $\mathrm{NH}_{4} \mathrm{Cl}(\mathrm{mmol} / \mathrm{L})$ & - & 5,72 & - & - \\
\hline $\mathrm{KH}_{2} \mathrm{PO}_{4}(\mathrm{mmol} / \mathrm{L})$ & - & - & 0,59 & - \\
\hline $\mathrm{Na}_{2} \mathrm{SO}_{4}(\mathrm{mmol} / \mathrm{L})$ & 4,79 & - & - & - \\
\hline $\mathrm{KSCN}(\mathrm{mmol} / \mathrm{L})$ & 2,06 & - & - & - \\
\hline $\mathrm{MgCl}_{2}(\mathrm{mmol} / \mathrm{L})$ & - & - & 0,53 & - \\
\hline $\mathrm{CaCl}_{2}{ }_{2 \mathrm{H} 2 \mathrm{O}}(\mathrm{mmol} / \mathrm{L})$ & - & 2,72 & 1,36 & 1,51 \\
\hline $\mathrm{HCl}(37 \%)(\mathrm{mL} / \mathrm{L})$ & - & 6,50 & 0,18 & 0,15 \\
\hline Urea $(\mathrm{mmol} / \mathrm{L})$ & 3,33 & 1,42 & 1,67 & 4,16 \\
\hline Glukosa (mmol/L) & - & 3,61 & - & - \\
\hline Azido glukuronikoa (mmol/L) & - & 0,10 & - & - \\
\hline Azido urikoa (mmol/L) & 0,09 & - & - & - \\
\hline Glukosamina hidrokloruroa (mmol/L) & - & 1,53 & - & - \\
\hline Behi-seroalbumina, A7906 (g/L) & - & 1,00 & 1,00 & 1,80 \\
\hline Muzina, M2378 (g/L) & 0,025 & 3,00 & - & - \\
\hline Alfa-amilasa, Aspergillus. oryzae-tik aterata, $10.065(\mathrm{~g} / \mathrm{L})$ & 0,29 & - & - & - \\
\hline Pepsina, txerri-mukosa gastrikotik aterata, P7125 (g/L) & - & 2,50 & - & - \\
\hline Lipasa, Aspergillus niger-tik aterata, 53.4781 (U/mL) & - & 100 & - & - \\
\hline Pankreatina, txerri-pankreatik aterata, P1750 (g/L) & - & - & 9,00 & - \\
\hline II. motako lipasa, txerri-pankreatik aterea, L3126 (g/L) & - & - & 1,50 & - \\
\hline Behi-behazuna, B3883 (g/L) & - & - & - & 18,75 \\
\hline $\mathrm{pH}$ & $6,8 \pm 0,2$ & $1,3 \pm 0,2$ & $8,1 \pm 0,2$ & $8,2 \pm 0,2$ \\
\hline
\end{tabular}




\subsection{Digestatoen buru-gunearen azterketa Fase Solidoko Mikroerauzketa-Gas Kromatografia/ Masa Espektrometria teknikaren bidez (SPME-GC/MS)}

Fase Solidoko Mikroerauzketa (SPME). Digestato guztien buru-gunearen konposatu lurrunkorren erauzketa $(0,5 \mathrm{~g}$ olio $10 \mathrm{~mL}-k o$ hari-tapoidun hodietan) automatikoki egin zen CombiPAL autosampler bat (Agilent Technologies, Santa Clara, CA, AEB) erabiliz. Erabilitako zuntza, zeina laginaren buru-gunean sartu zen eta han mantendu zen $50{ }^{\circ} \mathrm{C}$-an $60 \mathrm{mi}-$ nutuz orekara iritsi arte, Supelco enpresan (Sigma-Aldrich) erosi zen, eta DVB/CAR/PDMS polimeroarekin estalita zegoen (Dibinilbentzenoa/ karboxen/polidimetilsiloxanoa, 50/30 $\mu \mathrm{m}$ film-eko lodiera, $1 \mathrm{~cm}$-ko luzera) $[9,21,22]$. Erauzketa-kondizio egokienak aukeratu ahal izateko, zuntz mota (polaritatea eta estalkiaren materialaren lodiera) eta erauzketa kondizioak (lagin eta buru-gunearen bolumena, erauzketa denbora eta tenperatura) aldagaiak aurretiaz aztertu ziren gure laborategian.

Gas Kromatografia/ Masa Espektrometria (GC/MS). SPMEren bidez erauzitako konposatuak zituen zuntza 10 minutuz desorbatu zen GC7890A kromatografoaren injekzio portuan (splitless moduan 5 min-ko purgazio-denborarekin). Kromatrografo hori 5975C inert MSD masa selektiboen detektoreakin (Agilent Technologies) eta ChemStation programa duen ordenagailuarekin konektatuta dago. Erabilitako kromatografia-zutabea fused-silica capillary column zen $(60 \mathrm{~m}$-ko luzera $\times 0,25 \mathrm{~mm}$-ko barruko diametro x 0,25 $\mu \mathrm{m}$-ko lodiera, Agilent $J \& W$ Advanced Capillary GC Columns), zeina fase geldikorra apolar batez inguratuta zegoen (HP5MS, \%5 fenil-metil-siloxano). Lan-kondizioak honako hauek ziren: labearen hasierako tenperatura $50{ }^{\circ} \mathrm{C}$-koa zen $(5$ min-ko mantentze-denbora) eta, ondoren, $290{ }^{\circ} \mathrm{C}$-ra berotu zen, $4{ }^{\circ} \mathrm{C} / \mathrm{min}$-ko abiaduran. Interfasearen tenperatura $295{ }^{\circ} \mathrm{C}$-koa zen eta ioi-iturriaren eta kuadrupoloaren masa-analizagailuaren tenperaturak $230{ }^{\circ} \mathrm{C}$-an eta $150{ }^{\circ} \mathrm{C}$-an mantendu ziren, hurrenez hurren; gas-garraiatzale bezala, helioa erabili zen 18,611 psi presiotan; injektorea $250{ }^{\circ} \mathrm{C}$-an mantendu zen; masa-espektroak $70 \mathrm{eV}$-ko ionizazio-energian grabatu ziren; eta datu-lorpena Scan moduan egin zen (masa-espektroaren tartea: 40-tik 550-era $\mathrm{m} / \mathrm{z}$ ). Lehenengo desortzioaren ondoren, zuntza desortzio-baldintzara berriro eraman zen, garbitzeko asmoz. Konposatu-transferentzia arazoak (carry-over) saihesteko, prozesu bakoitzaren ondoren, zuntza CombiPAL autosampler-reko Fibre Cleaning and Conditioning Station-era eraman zen, $250{ }^{\circ} \mathrm{C}$-an beroketa jasatera 20 minutuz. Erreferentzia-lagin bat (hur-olio freskoa), zeinaren konposizioa ezaguna zen, aldizka analizatzen zen esperimentu honen benetako laginen artean, prozesu kromatografikoaren eta zuntzaren eraginkortasuna egiaztatzeko.

Konposatu gehienak Sigma-Aldrich enpresan erositako patroi komertzialak erabiliz identifikatu ziren. Patroirik ez zegoen kasuetan, erabilitako 
identifikazio-irizpidea izan zen lortutako masa-espektro ez-ezagunak literatura zientifikotik lortutakoekin alderatzea [23, 24] edota masa-espektroen liburutegi komertzial batekoekin (\%85a baino kointzidentzia handiagoa) (Wiley W9N08, Mass Spectral Database of the National Institute of Standards and Technology-NIST). Buru-guneen osagaien semi-kuantifikazioa konposatu bakoitzaren masa-espektroaren oinarrizko erpina (base peak) zati $10^{6}$ egitean oinarritu zen. Nahiz eta konposatu bakoitzaren kromatografia-erantzun faktorea ezberdina izan, egindako azalera-zenbaketa (area counts) erabilgarria da konposatu bakoitzak lagin ezberdinetan dituen ugaritasunak alderatzeko.

\subsection{Analisi estatistikoa}

Laginen emaitzen artean aurkitutako desberdintasunak estatistikoki esanguratsuak diren jakiteko, faktore bakarreko bariantza-analisia (ANOVA, Analysis of Variance) eta Tukey $b$ testa aplikatu ziren $(p<0.05)$, SPSS softwarea erabiliz (22. bertsioa, IBM enpresa, NY, AEB). Horretaz gain, oxidazio-konposatu lurrunkorren ugaritasunekin egindako Osagai Nagusien Analisia (ONA, Principal Component Analysis) egiteko, SIMCA izeneko softwarea erabili zen (v.15.0.2 Sartorius Stedim Data Analytics, Suedia).

\section{EMAITZAK ETA EZTABAIDA}

Orain dela hogei urte gutxi gorabehera argitaratu ziren lehenengo ikerlanak, zeinetan ikusten zen lipidoen digestioan hidrolisiaz gain oxidazioa ere gertatzen zela, digestio-aparatuaren kondizio prooxidatzaileek eraginda. Handik aurrera, ikerlan gehiago argitaratu dira gertaera hori frogatu eta gai horretan sakontzen dutenak [25]. Laburbilduz, oro har, bai edozein sistema biologikotan bai elikagaietan, lipidoen oxidazioa hasten denean, erradikal askeen eraginez, triglizeridoen azilo talde asegabeen egiturak eraldatu egiten dira, eta oxidazio-produktu primarioak sortu. Azken horiek oso erreaktiboak dira eta, eskuarki, dieno konjugatuak eta talde oxigenatu bat dituzte. Oxidazio-kondizioen arabera (tenperatura, denbora, substratu mota...) talde oxigenatu hau desberdina izango da: ezagunenak hidroperoxido taldeak dira, baina hidroxi- eta keto-taldeak ere izan daitezke. Oxidazio-produktu primario horiek oso ezegonkorrak direnez, azkar degradatzen dira, eta oxidazio-produktu sekundarioak sortzen dira. Horien artean, besteak beste, aldehidoak, zetonak, alkoholak, furanoak eta azidoak daude, zeinak lurrunkorrak edo ez-lurrunkorrak izan daitezkeen, molekulen tamainaren arabera. Era berean, tamaina handiko polimeroak ere sor daitezke. Ikerlan honetan, SPME-GC/MS teknikaren bidez aztertuko dira ur- 
dail-hesteetako in vitro digestioan sortutako oxidazio-produktu sekundario lurrunkorrak.

\subsection{BHTren eta BSAren efektua bakailao-gibel olio fresko eta oxidatuaren in vitro digestioan gertatutako lipidoen oxidazioan}

Analizatutako digestato guztien buru-gunean hainbat motatako oxidazio-konposatu sekundarioak aurkitu dira, kasurako, aldehidoak, zetonak, alkoholak eta furanoen eratorriak. Guztira 90 konposatu identifikatu dira (ikusi 2. taula). Konposatu horien ugaritasun-datuen gainean egindako Osagai Nagusien Analisiaren (ONA) emaitza grafikoak 2. irudian ematen dira. Irudiko a) atalean ikusten denez, lehenengo eta bigarren osagaiek bariantza osoaren $\% 84,4$ eta $\% 6,35$ azaltzen dute, hurrenez hurren. Bakailao-gibel olio oxidatuaren digestato guztiak lehenengo osagai nagusiaren alde negatiboan daude (DOx, DOx1-3, DOx + BSA) eta olio freskoaren lagin guztiak lehenengo osagai nagusiaren alde positiboan (DO, DO1-3, DO + BSA). Aldi berean, proteinarik gabeko digestato guztiak bigarren osagai nagusiaren alde negatiboan daude (DO, DO1-3, DOx, DOx1-3) eta BSA proteina dutenak bigarren osagai nagusiaren alde positiboan (DO + BSA, DOx + BSA). Laginen arteko bereizketa hori posible da sortutako oxidazio-konposatu sekundarioen ugaritasunengatik, 2. irudiko b) atalean ikusten den bezala, non ONAren aldagaien irudikapena ematen den. Espero zen bezala, oxidazio-konposatuak korrelazionatuta daude batik bat digeritu baino lehen jada oxidatuta zeuden digestatoekin, hau da, bakailao-gibel olio oxidatua zutenekin. Dena den, digestioan zehar lagin horietan lipidoen oxidazio-erreakzioaren hedatzea desberdina izan da, eta horregatik oxidazio-maila desberdinetara iritsi dira: DOx $>$ DOx $1>$ DOx2 > DOx3 > DOx + BSA (begiratu haien kokapena 2a irudian). Alegia, alde batetik, in vitro digestioan BHTak efektu antioxidatzailea izan du, bere kontzentrazioarekin erlazionatuta (zenbat eta kontzentrazio altuagoa, orduan eta efektu nabariagoa), eta bestetik, ikerlan honen baldintzetan BSA proteinak ere efektu antioxidatzailea izan du, BHTrena baino askoz agerikoagoa. Hala ere, kontuan izan behar da proteinarekin digeritutako laginetan oxidazio-konposatuen ugaritasun murriztuak izan daitezkeela, bai oxidazioaren aurrerapen txikiago batengatik, bai oxidazio-konposatu desberdinek (karboniloak nagusiki) proteinarekin gertatzen diren erreakzioengatik. 
2. taula. Digestatoen buru-guneetan SPME-GC/MS teknikaren bidez aurkitutako 90 oxidazio-konposatu sekundario lurrunkorrak eta haiei dagokien pisu molekularra $(\mathrm{Pm})$. Zenbakiak (Zk) bat datoz 2. irudiko b) atalean daudenekin.

\begin{tabular}{|c|c|c|c|c|c|}
\hline $\mathrm{Zk}$ & Konposatu lurronkorra $(\mathrm{Pm})$ & $\mathrm{Zk}$ & Konposatu lurronkorra $(\mathrm{Pm})$ & $\mathrm{Zk}$ & Konposatu lurronkorra $(\mathrm{Pm})$ \\
\hline & 1-Pentanola $(88)^{*}$ & 31 & Z,E-2,4-Undekadienala (166) & & Furanoa, pentil- (138)* \\
\hline & 1-Hexanola $(102)^{*}$ & 32 & E,E-2,4-Undekadienala (166) & 62 & Furanoa, 2-(2-Pentenil) (136) \\
\hline 3 & 5Z-Okta-1,5-dien-3-ola (126) & 33 & Pentanala $(86)^{*}$ & 63 & Furanoa, heptil- (166) \\
\hline & 1-Penten-3-ola $(86)^{*}$ & 34 & E-2-Pentenala is (84) & & 2,3-Butanediona (86) \\
\hline 5 & 1-Hexen-3-ola (100) & 35 & Hexanala $(100)^{*}$ & 65 & 2-Pentanona $(86)^{*}$ \\
\hline 6 & Z-2-Penten-1-ola $(86)^{*}$ & 36 & Heptanala $(114)^{*}$ & 66 & 2-Hexanona $(100)^{*}$ \\
\hline 7 & 1-Okten-3-ola (128)* & 37 & Oktanala $(128)^{*}$ & 67 & 4-Heptanona (114) \\
\hline 8 & Benzeneazetaldehidoa $(120)^{*}$ & 38 & Dekanala $(156)^{*}$ & & 3-Heptanona (114) \\
\hline 9 & Nonanala $(142)^{*}$ & 39 & Tridekanala (198) & 69 & 2-Oktanona $(128)^{*}$ \\
\hline 10 & Benzaldehidoa, 2-etil- (134) & 40 & Tetradekanala (212) & 70 & 2-Nonanona $(142)^{*}$ \\
\hline 11 & Benzaldehidoa, 3-etil- (134) & 41 & 2,4,7-Dekatrienala (150) & 71 & 2,3-Pentanediona $(100)^{*}$ \\
\hline 12 & Benzaldehidoa, 3,4-dimetil- (134) & 42 & Dekatrienala is (150) & & 2,3-Hexanediona (114) \\
\hline 13 & 4-Oxo-E-2-hexenala (112) & 43 & E-2-Propenala (56) & 73 & 2,5-Oktanediona (142) \\
\hline 14 & 4,5-Epoxi-2-heptenala (126) & 44 & E-2-Butenala $(70)^{*}$ & 74 & Oktadienona is (124) \\
\hline 15 & 4,5-Epoxi-2-heptenala is (126) & 45 & E-2-Pentenala (84)* & 75 & 3,5-Oktadien-2-ona (124) \\
\hline 16 & 4,5-Epoxi-2-dezenala (168) & 46 & Pentenala, 2-metil- (98) & 76 & 3,5 -Oktadien-2-ona is (124) \\
\hline 17 & 4,5-Epoxi-2-dezenala is (168) & 47 & E-2-Hexenala $(98)^{*}$ & 77 & 3,5-Nonadien-2-ona (138) \\
\hline 18 & E-2-Dezenala (154)* & 48 & Z-4-Heptenala $(112)^{*}$ & 78 & 3,5 -Nonadien-2-ona is (138) \\
\hline 19 & 2,4-Pentadienala (82) & 49 & E-2-Heptenala (112)* & 79 & 1-Penten-3-ona (84) \\
\hline 20 & E, E-2,4-Hexadienala (96) & 50 & E-2-Oktenala $(126)^{*}$ & 80 & 3-Penten-2-ona (84) \\
\hline 21 & Z, E-Heptadienala (110) & 51 & E-2-Nonenala $(140)^{*}$ & & 1-Hexen-3-ona (98) \\
\hline 22 & E, E-Heptadienala $(110)^{*}$ & 52 & Undekanala (170) & & 4-Hepten-2-ona (112) \\
\hline & Z, E-2,4-Oktadienala & 53 & E-Undezenala (168) & 83 & 1-Okten-3-ona (128) \\
\hline 24 & E, E-2,4-Oktadienala & 54 & Oktenala, 2-butil- (182) & 84 & 7-Okten-2-onaren is (126) \\
\hline & Z, E-2,6-Nonadienala (138) & 55 & E-Dodezenala (182) & & 3-Okten-2-ona (126) \\
\hline & E, E-2,6-Nonadienala (138) & 56 & E-Tridezenala (196) & 86 & 3-Nonen-2-ona (140) \\
\hline & Z, E-2,4-Nonadienala (138)* & 57 & E-Tetradezenala (210) & 87 & 3-Undezen-2-ona (168) \\
\hline & E, E-2,4-Nonadienala (138)* & 58 & Furanoa, 2-etil- (96) & 88 & 2(5H)Furanona, 5-etil- (112)* \\
\hline & Z, E-2,4-Dekadienala (152)* & 59 & Furanoa, 2-propil- (110) & 89 & 2(5H)-Furanona, 5-pentil- (154)* \\
\hline & E, E-2,4-Dekadienala $(152)^{*}$ & 60 & Furanoa, 2-butil- (124) & & Piridina, 2-etil- $(107)^{*}$ \\
\hline
\end{tabular}

Laburdura: is: isomeroa. *: patroi komertziala. 
a) SCORE SCATTER PLOT

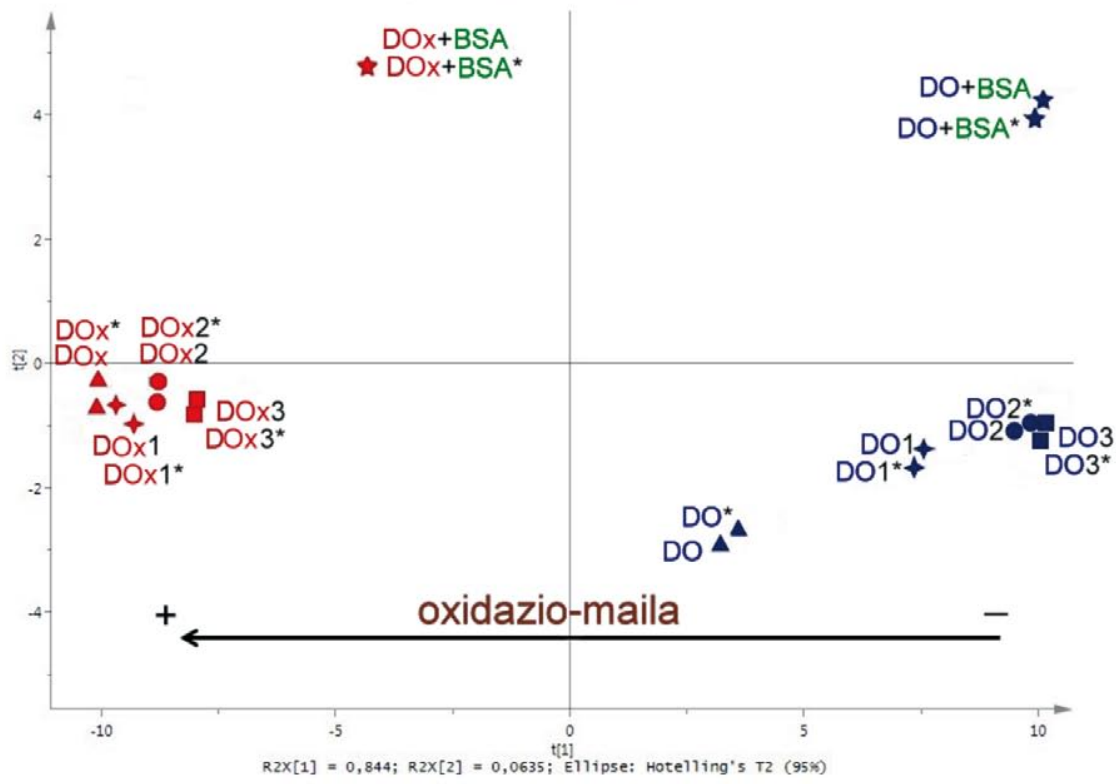

b) LOADING SCATTER PLOT

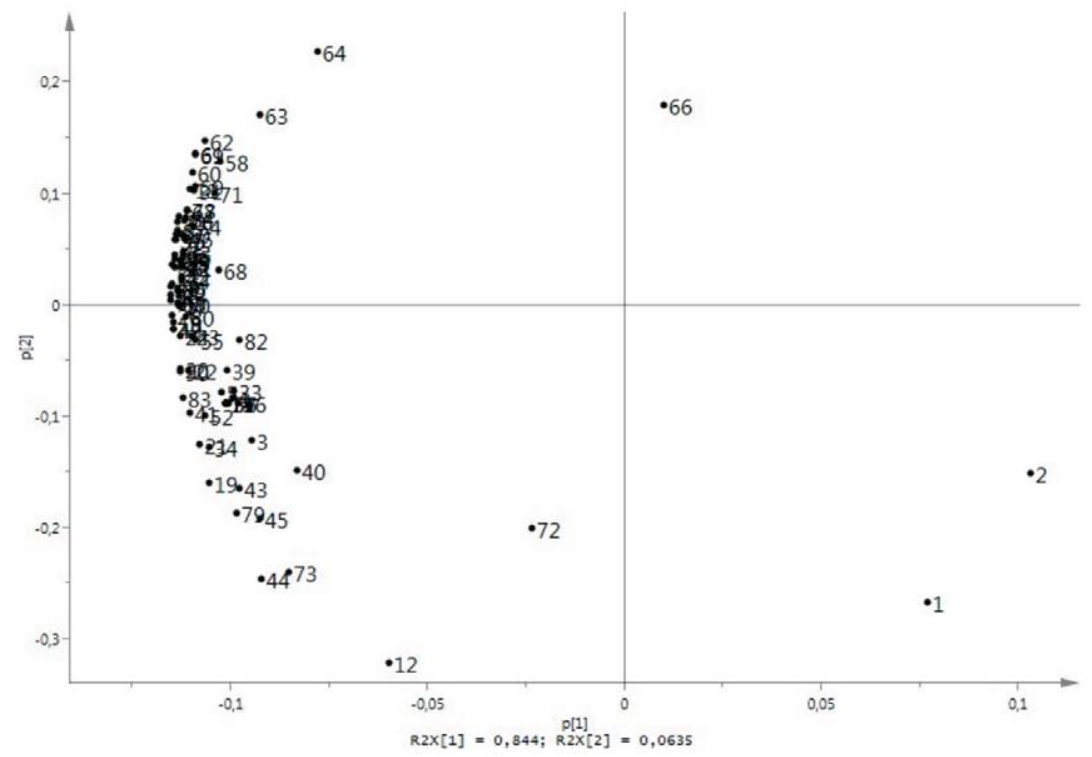

2. irudia. Digestatoen buru-gunean identifikatutako oxidazio-konposatu lurrunkorren ugaritasunekin egindako Osagai Nagusien Analisia (ONA). a) Digestatoen ONAren irudikapena eta b) ONAren aldagaien irudikapena (aldagaien zenbakiak bat datoz 2. taulan agertzen direnekin). *: laginaren errepikapena. 
Bakailao-gibel olio freskoaren digestatoei dagokienez, 2. irudiko a) atalean ikusten den bezala, eta espero zen bezala, haien oxidazio-maila bakailao-gibel olio oxidatuaren digestatoena baino askoz baxuagoa da. In vitro digestioan zehar olio freskoaren digestatoak oxidazio-maila desberdinetara iritsi dira: $\mathrm{DO}>\mathrm{DO} 1>\mathrm{DO} 2>\mathrm{DO} 3$, DO + BSA. Lagin horietan ere BHTak efektu antioxidatzailea dauka, kontzentrazioarekin erlazionatuta eta olio oxidatuaren digestatoetan baino nabariagoa (begiratu 2a irudia eta konparatu DOx eta DOx1-3-en arteko distantzia txikia, DO eta DO1-3-en arteko distantzia handiagoarekin). Gainera, azpimarratu behar da DO + BSA digestatoen oxidazio-maila eta DO3 digestatoena oso antzekoak direla, zeinek agerian uzten duen olio freskoen laginetan BSA proteinak ere efektu antioxidatzailea izan duela, baina ez dela izan olio oxidatuetan bezain nabaria (konparatu 2a irudian DOx + BSA eta DOx3 digestatoen arteko distantzia handia, eta DO + BSA eta DO3 digestatoen artekoa; azken bi horiek 2a irudiko lehenengo osagai nagusian ia kokapen bera dute).

\subsection{Bakailao-gibel olio fresko eta oxidatuaren in vitro digestioan zehar gertatutako BHTren murrizketa}

Ezaguna da konposatu antioxidatzaile batek lipidoen oxidazioa saihesten duenean bere estruktura bera oxidatzen dela eta, ondorioz, degradatzen dela, hainbat eratorritako metabolito sortuz. Behin antioxidatzaile baten kantitate osoa degradatuta, horrek jada ez dauka efektu antioxidatzailerik eta, hortaz, lipidoen oxidazioa mugarik gabe aurrera joaten da. Gauzak horrela, digestioaren ondoren zenbat eta degradatu gabeko antioxidatzaile kantitate handiagoa aurkitu, orduan eta txikiagoa oxidazioaren hedatzea.

3. irudian erakusten dira aurkitutako BHTren ugaritasunak digestato guztietan. Hitz batez, BHTren kontzentrazio berdineko laginak elkarren artean konparatzen badira $(1,2,3)$, olio freskoaren digestatoetan BHTren ugaritasun handiagoak aurkitu dira, olio oxidatuaren digestatoekin konparatuta. Horrek adieraziko luke oxidazio-erreakzioak gehiago aurreratzen direla olio oxidatuaren digestioan zehar olio freskoaren digestioan baino. 


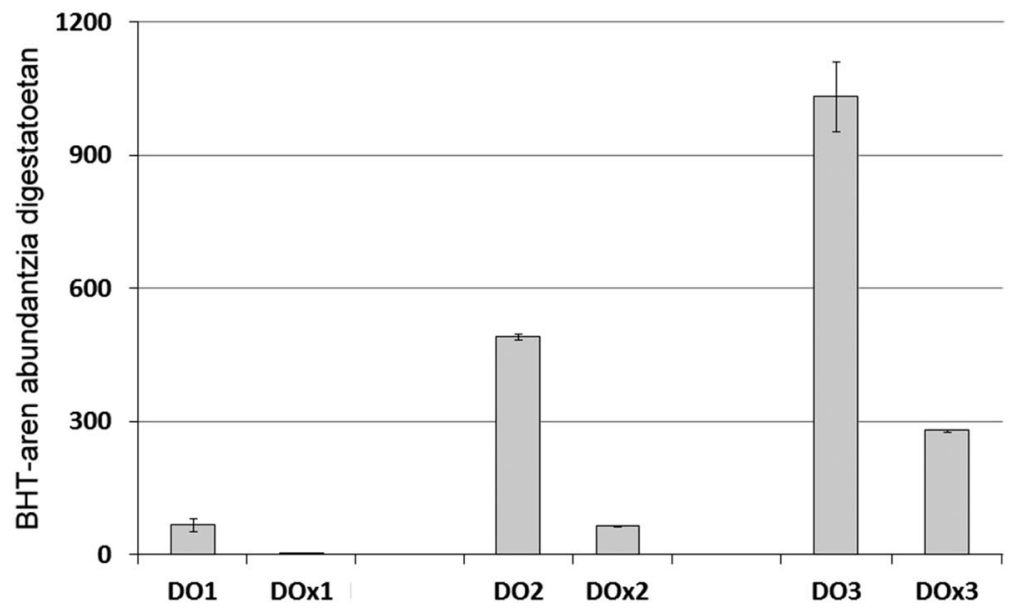

3. irudia. BHTren ugaritasuna (azalera-zenbaketa zati $10^{6}$-tan adierazita) hurrengo digestatoen buru-guneetan: digeritutako bakailao-gibel olio fresko eta oxidatua, $20 \mathrm{mg} / \mathrm{kg}$ olio (DO1, DOx1), $200 \mathrm{mg} / \mathrm{Kg}$ olio (DO2, DOx2) eta $800 \mathrm{mg} / \mathrm{Kg}$ olio (DO3, DOx3) BHTrekin aberastuta.

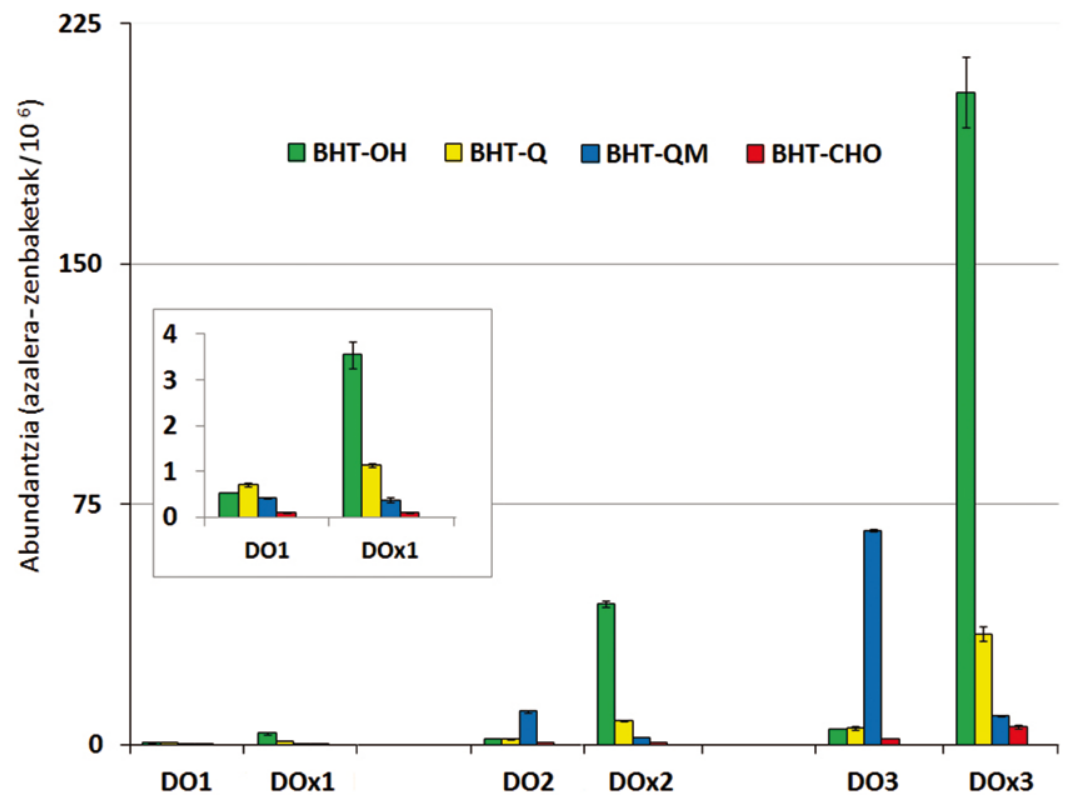

4. irudia. BHTren metabolito lurrunkorren ugaritasunak (azalera-zenbaketa zati $10^{6}$-tan adierazita) hurrengo digestatoen buru-espazioan: digeritutako bakailao-gibel olio freskoa eta oxidatua, $20 \mathrm{mg} / \mathrm{kg}$ olio (DO1, DOx1), $200 \mathrm{mg} / \mathrm{Kg}$ olio (DO2, DOx2) eta $800 \mathrm{mg} / \mathrm{Kg}$ olio (DO3, DOx3) BHTrekin aberastuta. 


\subsection{BHTtik eratorritako metabolito lurrunkorren presentzia}

Lehen azaldu bezala, BHTak antioxidatzaile moduan jokatzen badu lipidoen oxidazioa atzeratzeko, bere burua oxidatzen da, eta zenbait metabolito sortu. Digestato guztietan lau BHT-metabolito aurkitu dira: 2,6-di-tert-butil-4-hidroxi-4-metil-2,5-ziklohexadien-1-ona (BHT-OH), 2,6-di-tert-butil-2,5-ziklohexadien-1,4-diona (BHT-Q), 3,5-di-tert-butil-4hidroxi-benzaldehidoa (BHT-CHO) eta 2,6-di-tert-butil-4-metilene-2,5-ziklohexadien-1-ona (BHT-QM). Lau metabolito horien ugaritasunak handiagoak dira olio oxidatuaren digestatoetan olio freskoaren digestatoetan baino (DO1x > DO1, DO2x > DO2, DO3x > DO3). Emaitza hori bat dator lehen azaldutakoarekin BHTren presentziaren gainean digestatoetan (ikusi 3. irudia). Azpimarratzekoa da DOx2 eta DOx3 digestatoetan, non BHTren degradazio nabaria ikusi den (begiratu 3. irudia), sortutako metabolito nagusia BHT-OH izan dela. Sistema biologikoetan BHT-metabolito hauen sorrerarako proposatutako mekanismoak 5. irudian laburtzen dira [11]. Ikusi da nola BHT-CHO, BHT-Q eta BHT-QM metabolitoak azido desoxirribonukleikoaren (DNA) in vitro zatiketa eragiteko gai diren [26]. Kalte horren intentsitatearen eta zelularen konpontzeko ahalmenaren arabera, kartzinogenesi-arriskua desberdina izango da. Dena den, azpimarratu behar da metabolito hauen ugaritasunak oso txikiak direla. Hala ere, ikerketa gehiagoren beharra dago haien kontzentrazio absolutua kalkulatzeko, bai eta azken horiek osasunaren ikuspuntutik kezkagarriak izan litezkeela jakiteko ere.

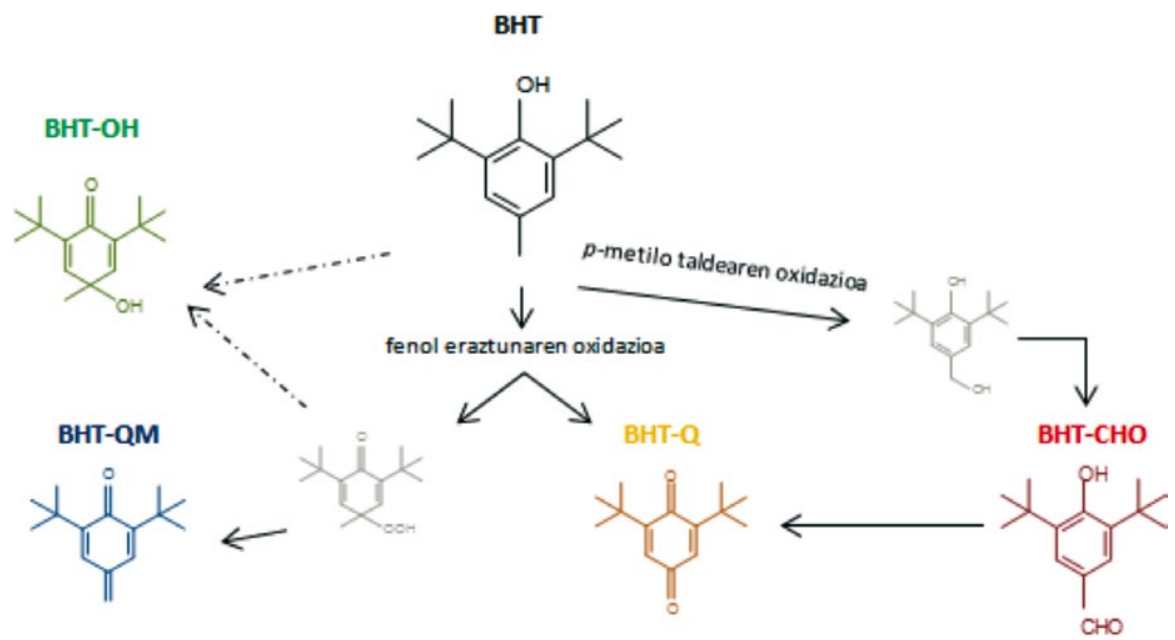

5. irudia. Sistema biologikoetan proposatutako BHTren oxidazio-prozesuak eta horien ondorioz sortutako metabolitoak [11]. 


\section{ONDORIOAK}

Ikerlan honek agerian utzi du bakailao-gibel olio freskoaren eta oxidatuaren urdail-hesteetako in vitro digestioan BHTak eta BSA proteinak efektu antioxidatzaile nabaria dutela. Aipatu behar da erabilitako baldintza esperimentaletan BSA proteinaren ahalmen antioxidatzailea nabarmenagoa izan dela, batik bat olio oxidatuaren digestatoetan. Halaber, olio freskoaren digestatoekin alderatuta, olio oxidatuaren digestatoetan ikusi da lipidoen oxidazioaren hedatzea handiagoa izan dela, eta ondorioz BHT gehiago degradatu dela, eta hainbat BHT-metabolito sortu (BHT-OH, BHT-Q, BHTCHO eta BHT-QM).

\section{ESKER ONAK}

Artikulu hau Espainiako Ekonomia, Industria eta Lehiakortasuneko Ministerioak (MINECO, AGL2015-65450-R), Eusko Jaurlaritzako Hezkuntza Saileko Unibertsitate eta Ikerketa lan-arloak (EJ-GV, IT-916-16) eta Ekonomiaren Garapen eta Azpiegitura Saileko Nekazaritza, Arrantza eta Elikagai industria lan-arloak (EJ-GV, PA19/02) finantzatu dute.

\section{BIBLIOGRAFIA}

[1] BIESALSKI H. K. 2011. «Vitamin D Recommendations-Beyond Deficiency». Annals of Nutrition \& Metabolism, 59(1), 10-16.

[2] LOFTSSON T., ILIEVSKA B., ASGRIMSDOTTIR G. M., ORMARSSON O. T., eta STEFANSSON E. 2016. «Fatty acids from marine lipids: Biological activity, formulation and stability». Journal of Drug Delivery Science and Technology, 34, 71-75.

[3] FRANKEL E. N. 2005. Lipid oxidation. The Oily Press, Bridgewater.

[4] TURNER R., MCLEAN C. H. eta SILVERS K. M. 2006. «Are the health benefits of fish oils limited by products of oxidation?». Nutrition Research Reviews, 19(1), 53-62.

[5] LARSSON K., CAVONIUS L., ALMINGER M. eta UNDELAND I. 2012. «Oxidation of cod liver oil during gastrointestinal in vitro digestion». Journal of Agricultural and Food Chemistry, 60(30), 7556-7564.

[6] KRISTINOVA V., STORRø I. eta RUSTAD T. 2013. «Influence of human gastric juice on oxidation of marine lipids-in vitro study». Food Chemistry, 141(4), 3859-3871.

[7] KENMOGNE-DOMGUIA H. B., MOISAN S., VIAU M., GENOT C. eta MEYNIER A. 2014. «The initial characteristics of marine oil emulsions and the composition of the media inflect lipid oxidation during in vitro gastrointestinal digestion». Food Chemistry, 152, 146-154. 
[8] TUlLbERG C., LARSSON K., CARLSSON N-G., COMI I., SCHEERS N., VEGARUD G., eta UNDELAND I. 2016. «Formation of reactive aldehydes (MDA, HHE, HNE) during the digestion of cod liver oil: comparison of human and porcine in vitro digestion models». Food \& Function, 7(3), 1401-1412.

[9] NIEVA-ECHEVARRIA B., GOICOECHEA E. eta GUILLEN, M. D. 2017. «Polyunsaturated lipids and vitamin A oxidation during cod liver oil in vitro gastrointestinal digestion. Antioxidant effect of added BHT». Food Chemistry, 232, 733-743.

[10] TULLBERG C., VEGARUD G. eta UNDELAND I. 2019. «Oxidation of marine oils during in vitro gastrointestinal digestion with human digestive fluids-Role of oil origin, added tocopherols and lipolytic activity». Food Chemistry, 270, 527-537.

[11] NIEVA-ECHEVARRÍA B., MANZANOS M. J., GOICOECHEA E. eta GUILLÉN M. D. 2015. «2,6-Di-tert-butyl-hydroxytoluene and its metabolites in foods». Comprehensive Reviews in Food Science and Food Safety, 14(1), 67-80.

[12] KUFFA M., PRIESBE T. J., KRUEGER C. G., REED J. D. eta RICHARDS M. P. 2009. «Ability of dietary antioxidants to affect lipid oxidation of cooked Turkey meat in a simulated stomach and blood lipids after a meal». Journal of Functional Foods, 1(2), 208-216.

[13] TARVAINEN M., PHUPHUSIT A., SUOMELA J-P., KUKSIS A. eta KALLIO H. 2012. «Effects of antioxidants on rapeseed oil oxidation in an artificial digestion model analyzed by UHPLC-ESI-MS». Journal of Agricultural and Food Chemistry, 60(14), 3564-3579.

[14] ELIAS R. J., KELLERBY S. S. eta DECKER E. A. 2008. «Antioxidant activity of proteins and peptides». Critical Reviews in Food Science and Nutrition, 48(5), 430-441.

[15] REMANAN M. K., eta WU J. 2014. «Antioxidant activity in cooked and simulated digested eggs». Food \& Function, 5(7), 1464-1474.

[16] BORAWSKA J., DAREWICZ M., VEGARUD G. E., IWANIAK A., eta MINKIEWICZ P. 2015. «Ex vivo digestion of carp muscle tissue-ACE inhibitory and antioxidant activities of the obtained hydrolysates». Food \& Function, 6(1), 211-218.

[17] PRIOR R. L., WU X. eta SCHAICH K. 2005. «Standardized methods for the determination of antioxidant capacity and phenolics in foods and dietary supplements». Journal of Agricultural and Food Chemistry, 53(10), 42904302.

[18] REGLAMENTO (UE) No 1129/2011 DE LA COMISIÓN EUROPEA de 11 de noviembre de 2011 por el que se modifica el anexo II del Reglamento (CE) no 1333/2008 del Parlamento Europeo y del Consejo para establecer una lista de aditivos alimentarios de la Unión.

[19] VERSANTVOORT C. H. M., OOMEN A. G., VAN DE KAMP E., ROMPELBERG C. J. M. eta SIPS A. J. A. M. 2005. «Applicability of an in vitro 
digestion model in assessing the bioaccessibility of mycotoxins from food». Food and Chemical Toxicology, 43(1), 31-40.

[20] NIEVA-ECHEVARRÍA B., GOICOECHEA E., MANZANOS M. J. eta GUILLÉN M. D. 2016. «A study by ${ }^{1} \mathrm{H}$ NMR on the influence of some factors affecting lipid in vitro digestion». Food Chemistry, 211, 17-26.

[21] ZARATE J., GOICOECHEA E., PASCUAL J., ECHEVARRIA E. eta GUILLÉN M. D. 2009. « A study of the toxic effect of oxidized sunflower oil containing 4-hydroperoxy-2-nonenal and 4-hydroxy-2-nonenal on cortical TrkA receptor expression in rats ». Nutritional Neuroscience, 12(6), 249259.

[22] GUILlÉN M. D., CABO N., IBARGOITIA M. L. eta RUIZ A. 2005. « Study of both sunflower oil and its headspace throughout the oxidation process. Occurrence in the headspace of toxic oxygenated aldehydes». Journal of Agricultural and Food Chemistry, 53(4), 1093-1101.

[23] SCHUH C. eta SCHIEBERLE P. 2005. «Characterization of (E,E,Z)-2,4,6Nonatrienal as a character impact aroma compound of oat flakes». Journal of Agricultural and Food Chemistry, 53(22), 8699-8705.

[24] HAMMER M. eta SCHIEBERLE P. 2013. «Model studies on the key aroma compounds formed by an oxidative degradation of omega- 3 fatty acids initiated by either copper (II) ions or lipoxygenase». Journal of Agricultural and Food Chemistry, 61(46), 10891-10900.

[25] NIEVA-ECHEVARRÍA B., GOICOECHEA E. eta GUILLÉN M. D. 2019. «Food lipid oxidation under gastrointestinal digestion conditions: a review». Critical Reviews on Food Science and Nutrition. Ahead of print. doi: 10.1080/10408398.2018.1538931.

[26] NAGAI F., USHIYAMA K. eta KANO I. 1993. «DNA cleavage by metabolites of butylated hydroxytoluene». Archives of Toxicology, 67(8), 552-557. 